\title{
Quality Assurance Plan for Federal Guidance Report 16
}

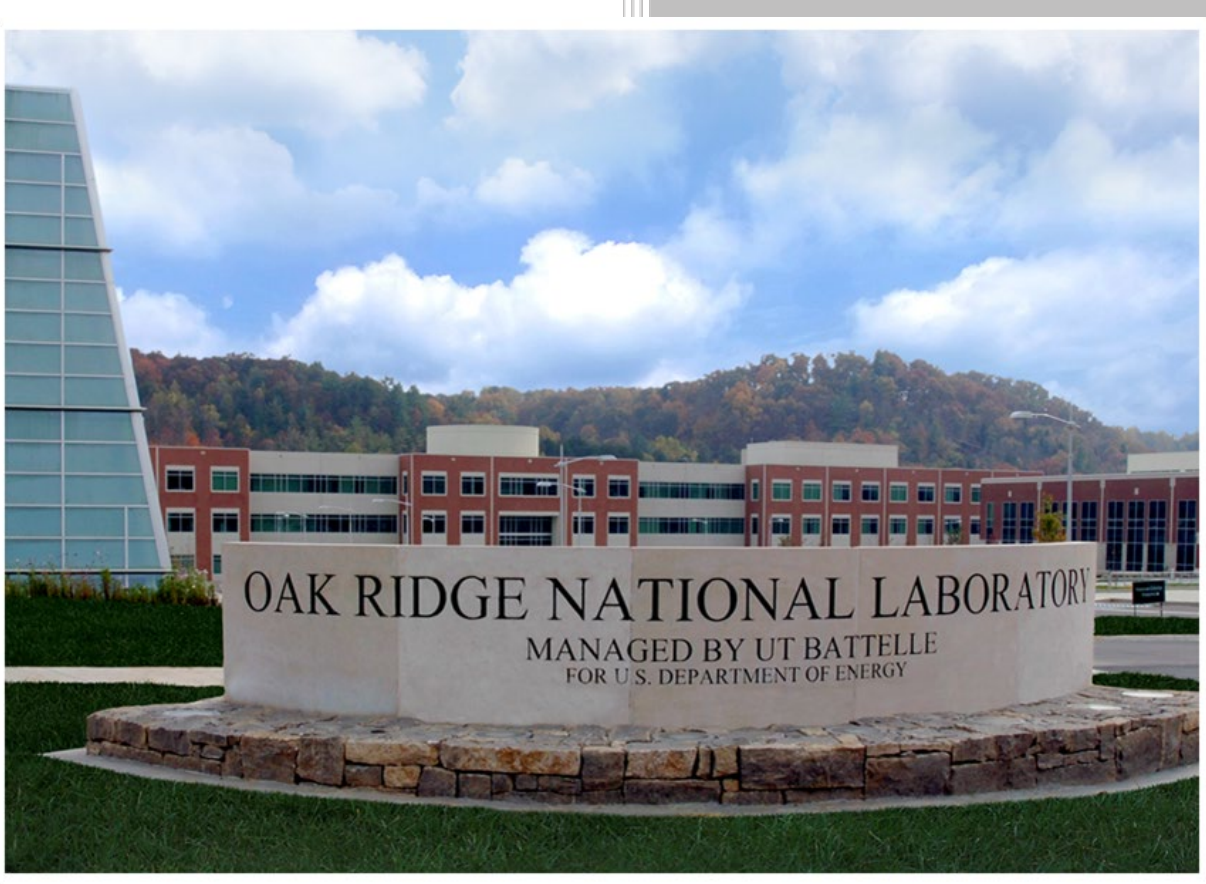

Nicole Martinez

Clay Easterly Keith Eckerman Mauritius Hiller Derek Jokisch Caleigh Samuels Richard Ward Rich Leggett

November 2020 


\title{
DOCUMENT AVAILABILITY
}

Reports produced after January 1, 1996, are generally available free via US Department of Energy (DOE) SciTech Connect.

Website www.osti.gov

Reports produced before January 1, 1996, may be purchased by members of the public from the following source:

\author{
National Technical Information Service \\ 5285 Port Royal Road \\ Springfield, VA 22161 \\ Telephone 703-605-6000 (1-800-553-6847) \\ TDD 703-487-4639 \\ Fax 703-605-6900 \\ E-mail info@ntis.gov \\ Website http://classic.ntis.gov/
}

Reports are available to DOE employees, DOE contractors, Energy Technology Data Exchange representatives, and International Nuclear Information System representatives from the following source:

Office of Scientific and Technical Information

PO Box 62

Oak Ridge, TN 37831

Telephone 865-576-8401

Fax 865-576-5728

E-mail reports@osti.gov

Website http://www.osti.gov/contact.html

This report was prepared as an account of work sponsored by an agency of the United States Government. Neither the United States Government nor any agency thereof, nor any of their employees, makes any warranty, express or implied, or assumes any legal liability or responsibility for the accuracy, completeness, or usefulness of any information, apparatus, product, or process disclosed, or represents that its use would not infringe privately owned rights. Reference herein to any specific commercial product, process, or service by trade name, trademark, manufacturer, or otherwise, does not necessarily constitute or imply its endorsement, recommendation, or favoring by the United States Government or any agency thereof. The views and opinions of authors expressed herein do not necessarily state or reflect those of the United States Government or any agency thereof. 
Environmental Sciences Division

Center for Radiation Protection Knowledge

\title{
QUALITY ASSURANCE PLAN FOR FEDERAL GUIDANCE REPORT 16
}

\author{
Nicole Martinez, Clay Easterly, Keith Eckerman, \\ Mauritius Hiller, Derek Jokisch, Caleigh Samuels, \\ Richard Ward, Rich Leggett
}

Date Published: November 2020

\author{
Prepared by \\ OAK RIDGE NATIONAL LABORATORY \\ Oak Ridge, TN 37831-6283 \\ managed by \\ UT-BATTELLE, LLC \\ for the \\ US DEPARTMENT OF ENERGY \\ under contract DE-AC05-00OR22725
}

The work described in this document was sponsored by the Office of Radiation and Indoor Air, U. S. Environmental Protection Agency (EPA), under Interagency Agreement DOE No. 1824 S581-A1, under contract No. DE-AC05-00OR22725 with UT-Battelle. 



\section{CONTENTS}

CONTENTS

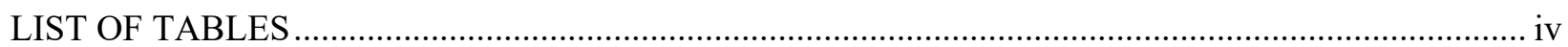

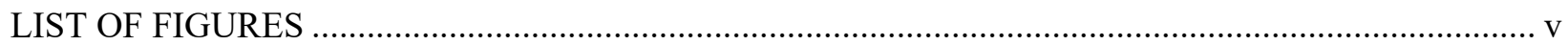

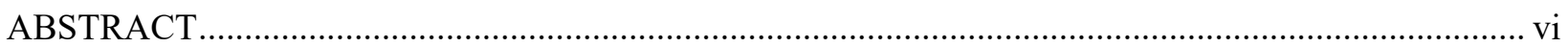

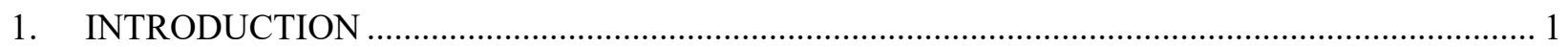

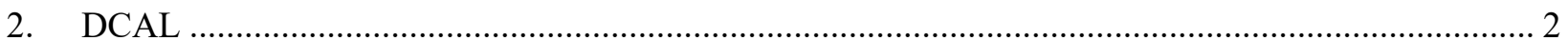

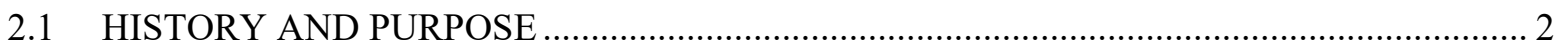

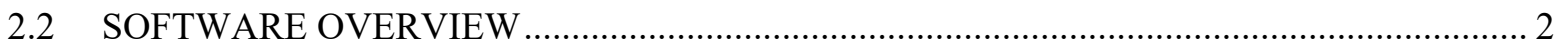

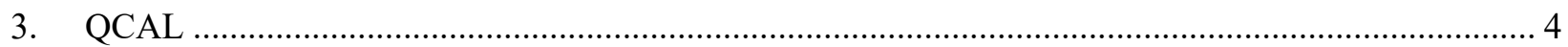

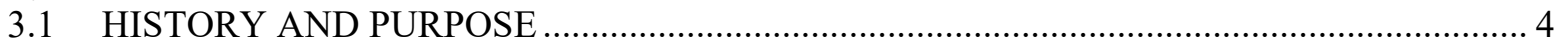

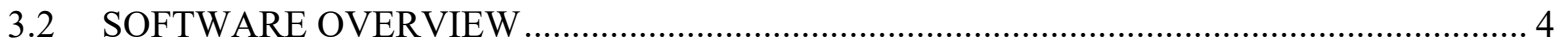

4. SOURCES AND QUALITY ASSURANCE OF INPUT DATA …................................................ 4

4.1 USING PEER-REVIEWED AND PUBLISHED DATA AS SOURCES OF THE

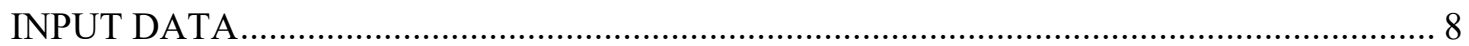

4.1.1 NUCLEAR DECAY DATA

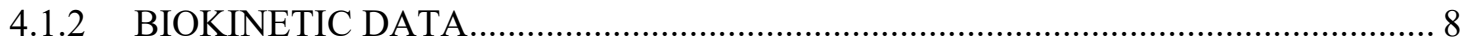

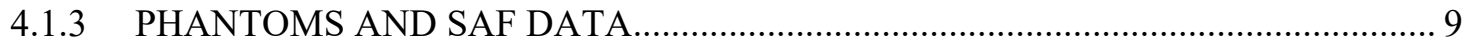

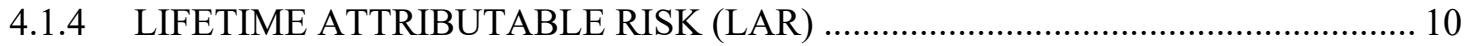

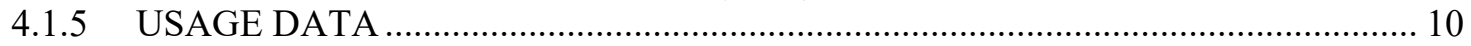

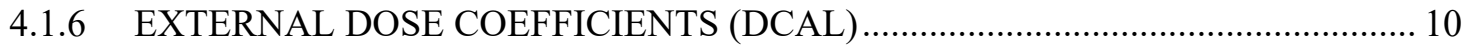

4.2 NOT ALTERING THE DATA FILES FROM THEIR ORIGINAL FORM ......................... 10

4.3 USING VERSION CONTROL FOR DEVELOPMENT OF INPUT DATA .......................... 10

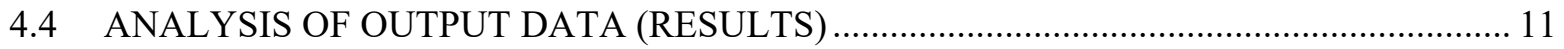

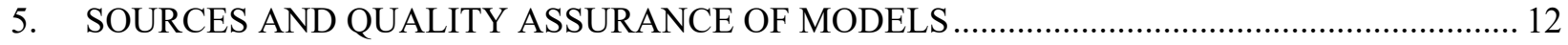

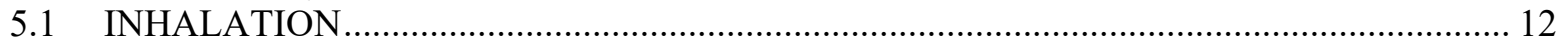

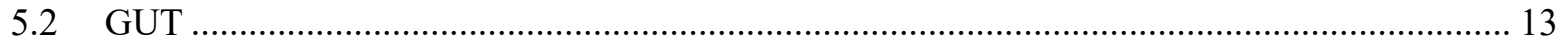

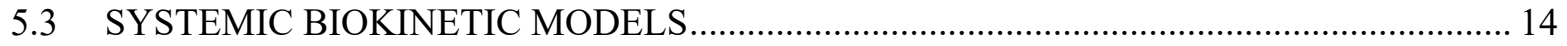

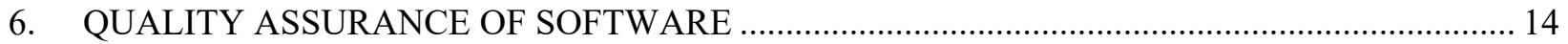

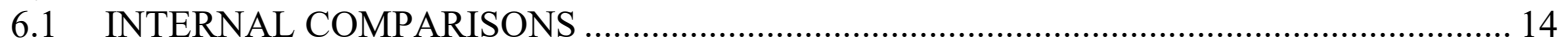

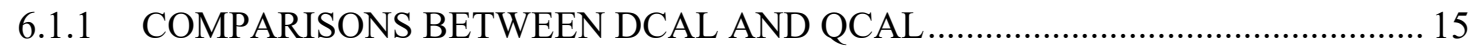

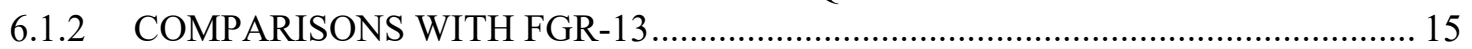

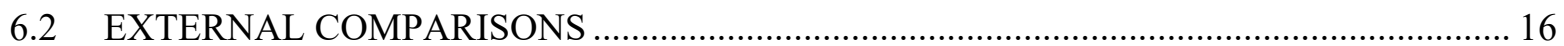

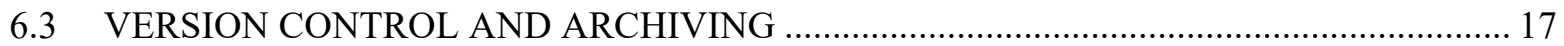

6.4 DCAL BETA TEST FEEDBACK AND IMPLEMENTATION .......................................... 18

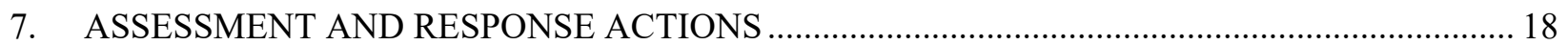

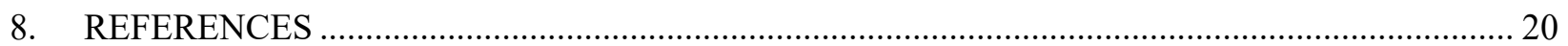




\section{LIST OF TABLES}

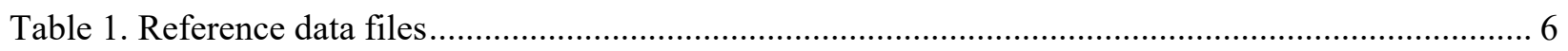

Table 2. Regional deposition of aerosol (1 $\mu \mathrm{m}$ AMAD) for reference individuals. .................................. 13

Table 3. Age-specific HATM transfer coefficients for total diet ........................................................ 14

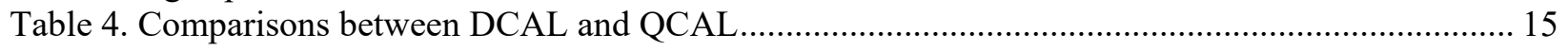




\section{LIST OF FIGURES}

Figure 1: Schematic of the DCAL computational software ................................................................... 3

Figure 2: The three codes that comprise QCAL. On the left-hand side is input data for each code

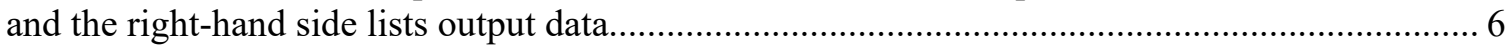

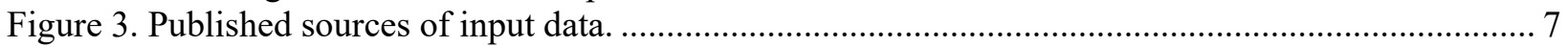

Figure 4: Example visualization of select SAFs vs. energy for QA review. For certain ages, electron SAFs for ET1-bas $\leftarrow$ ET1-wall were switched in both sexes; QA enabled changes to be implemented prior to final calculation of dose and risk coefficients. ......

Figure 5: Screenshot of a cloud repository coupled with Git for SAF development. .............................. 11

Figure 6a: Number of nuclear transformations (integrated activity) broken up by source region for

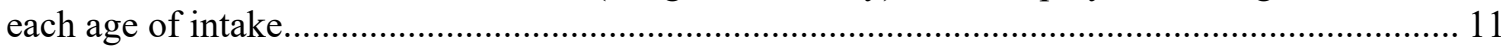

Figure 6b: Committed absorbed dose coefficient for inhalation of type F I-131 for each reference

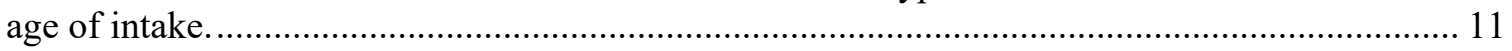

Figure 7: Mortality comparison between QCAL and FGR 13 for three example cases. .......................... 16

Figure 8: Summary of the comparisons of QCAL output data with other sources of the same

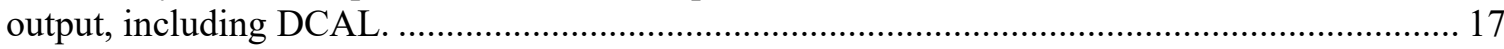

Figure 9: Git cloud repository screenshot for QCAL. It shows the details of one particular change (commit). 


\begin{abstract}
Federal Guidance Report No. 16 will provide risk coefficients for use in projecting the probability of cancer morbidity or mortality from exposure to environmental radionuclides. The derivation of nuclide-specific risk coefficients involves multiple steps, with each step relying on the accuracy of the previous step as well as the numerical data utilized within each step. Thus, to ensure the quality of the derived risk coefficients, it is necessary to evaluate and confirm the quality and proper implementation of input data at each step of the derivation. The Oak Ridge National Laboratory (ORNL) dosimetry research team currently has two largely independent software codes for deriving radiation dose estimates, dose coefficients, and cancer risk coefficients for internally deposited radionuclides: DCAL and QCAL. The agreement of derived values based on alternate codes is an important step in quality assurance (QA) of the risk coefficients produced in this project. DCAL is an integration of the dosimetric software and numerical databases developed at ORNL over the past 25 years for the EPA's Office of Radiation and Indoor Air (ORIA). QCAL was developed in 2015 to serve as a substitute for DCAL while DCAL was undergoing revision and to provide QA for the updated version of DCAL. The complex methodology employed in the derivation of cancer risk coefficients presents a challenge for QA, and as such, this report describes the QA steps used by the ORNL dosimetry team in this process as implemented in DCAL and QCAL for Federal Guidance Report No. 16.
\end{abstract}




\section{INTRODUCTION}

The overall goal of the Federal Guidance Report No. 16 (FGR-16) project is to develop revised risk coefficients for estimating health risk from internal or external exposure to radionuclides through the application of state-of-the-art methods and models. The mathematical models take into account age dependence of biokinetics and both age and gender dependence of environmental usage, dosimetry, radiogenic risk, and competing cases of death, consistent with internationally accepted models and procedures. This document summarizes the primary quality assurance (QA) efforts undertaken with respect to the computation of the dose and risk coefficients associated with the report.

Since the mid-1980s the Environmental Protection Agency (EPA) has issued a series of Federal Guidance Reports that provide Federal and State agencies technical information to assist their implementation of radiation protection programs. For many years, the Center for Radiation Protection Knowledge (CRPK) and its predecessor, the Dosimetry Research Group, at Oak Ridge National Laboratory (ORNL) have provided technical support for EPA's series of Federal Guidance Reports on radiation protection. This technical support involves development and application of biokinetic and dosimetric models for radionuclides and the collection and dissemination of technical information on radiation protection and its practices. The tasks include supporting and monitoring the development of new models and updated nuclear data, dose coefficients, and bioassay tables based on the latest primary guidance for radiation protection from the International Commission on Radiological Protection (ICRP). The biokinetic and dosimetric models developed or collected by CRPK are used in the derivation of dose and risk coefficients tabulated in Federal Guidance Reports.

The Federal Guidance Reports have provided dose coefficients for estimating radiation dose due to exposure to radionuclides and in some cases have tabulated exposure guidelines for radionuclides based on these dose coefficients. Federal Guidance Report No. 13 (FGR-13), Cancer Risk Coefficients for Environmental Exposure to Radionuclides (Eckerman et al., 1999), was the first in this series of reports to provide risk coefficients for estimating health risk from exposure to radionuclides. Since the completion of FGR-13, substantial improvements have been made in some of the models and data sets used to develop the cancer risk coefficients tabulated in that report:

- Updated biokinetic models describing the behavior of internally deposited radionuclides in the respiratory and alimentary tracts and after absorption to blood (systemic models) for different age groups (ICRP, 2020a).

- Updated dosimetric models reflecting more sophisticated computational phantoms for different ages and both sexes (ICRP, 2020a).

- Updated nuclear decay data for a substantially expanded set of radionuclides of potential significance in occupational or environmental settings (ICRP, 2008).

- Updated radiation risk models based primarily on a review by the National Academy of Sciences on the Biological Effects of Ionizing Radiation (NAS, 2006; EPA, 2011a).

- Updated mortality rates, cancer incidence rates, and environmental usage rates appropriate for the US population.

The update of FGR-13 will ensure that the Federal Guidance Report series remains consistent with the latest internationally adopted radiation protection models and standards as well as current US demographic data. FGR-16 will provide numerical coefficients for use in estimating the risk of cancer from exposure to radionuclides in the environment. A risk coefficient for a radionuclide that exposes persons through a given environmental medium is an estimate of the probability of radiogenic cancer morbidity or mortality per unit activity intake for internal exposure, or per unit exposure for external exposures. 
The derivation of nuclide-specific risk coefficients involves multiple steps, with each step relying on both the accuracy of the previous step as well as correct access to and application of additional numerical data at each step. This approach, while necessary, presents a challenge for QA of the derived risk coefficients. To ensure the quality of the results provided in FGR-16 it is necessary to assure the quality of input data and at each calculational step to identify the data files accessed. Additionally, the age and sex specific dose and risk coefficients are compared to previously published results to ensure that differences from the earlier data are of the expected magnitude.

The ORNL dosimetry research team currently has two largely independent software codes for deriving dose estimates, dose coefficients, and cancer risk coefficients for internally deposited radionuclides. The agreement of derived values based on alternate codes is an important step in QA of the risk coefficients produced in this project. The two codes are referred to as DCAL and QCAL. DCAL is an integration of the dosimetric software and numerical databases developed at ORNL over the past twenty years for the EPA's Office of Radiation and Indoor Air (ORIA). QCAL was developed in 2015 to serve as a substitute for DCAL while it was undergoing revision and to provide QA for the updated version of DCAL.

\section{DCAL}

\subsection{HISTORY AND PURPOSE}

DCAL was initially designed to compute dose coefficients for occupational and environmental intakes of radionuclides and to serve as a source of stored dose coefficients for external exposure to radionuclides. DCAL has been used by task groups of the ICRP Committee 2 in the production of several ICRP publications. DCAL was also used to produce FGR-13. DCAL is designed to generate tabulations of dose rate coefficients to tissues as a function of time (age) post intake, a feature that is required for derivation of risk coefficients. DCAL performs calculations for intake of a radionuclide by inhalation, ingestion, or injection into blood, using libraries of input parameters discussed in Section 4 below.

DCAL has undergone progressive revisions, updates, and improvements since its original inception. DCAL was originally a DOS program and was updated to run on Windows and later updated for 64-bit CPUs. DCAL and its input files have been periodically updated to reflect advances in radiation protection data and models.

\subsection{SOFTWARE OVERVIEW}

DCAL has been used by the ORNL dosimetry research team since the early 1990s to derive the radiation protection quantities tabulated in several Federal Guidance Reports and ICRP reports and hence has been subject to considerable QA efforts. The DCAL system makes use of extensively reviewed data files to limit the amount of information the user must provide and thus reducing the potential for input errors.

The DCAL software package consists of four primary computational modules containing additional secondary modules. The primary modules are all accessed via a windows-based menu. Figure 1 shows these computational modules and the various data elements used in the derivation of radionuclide-specific risk coefficients. The four rectangular elements are the computational modules (ACTACAL, S-CAL, EPACAL, and RISKCAL) and the cylindrical elements represent the various data elements that the modules access in computing the risk coefficient for a specified radionuclide and exposure mode. 


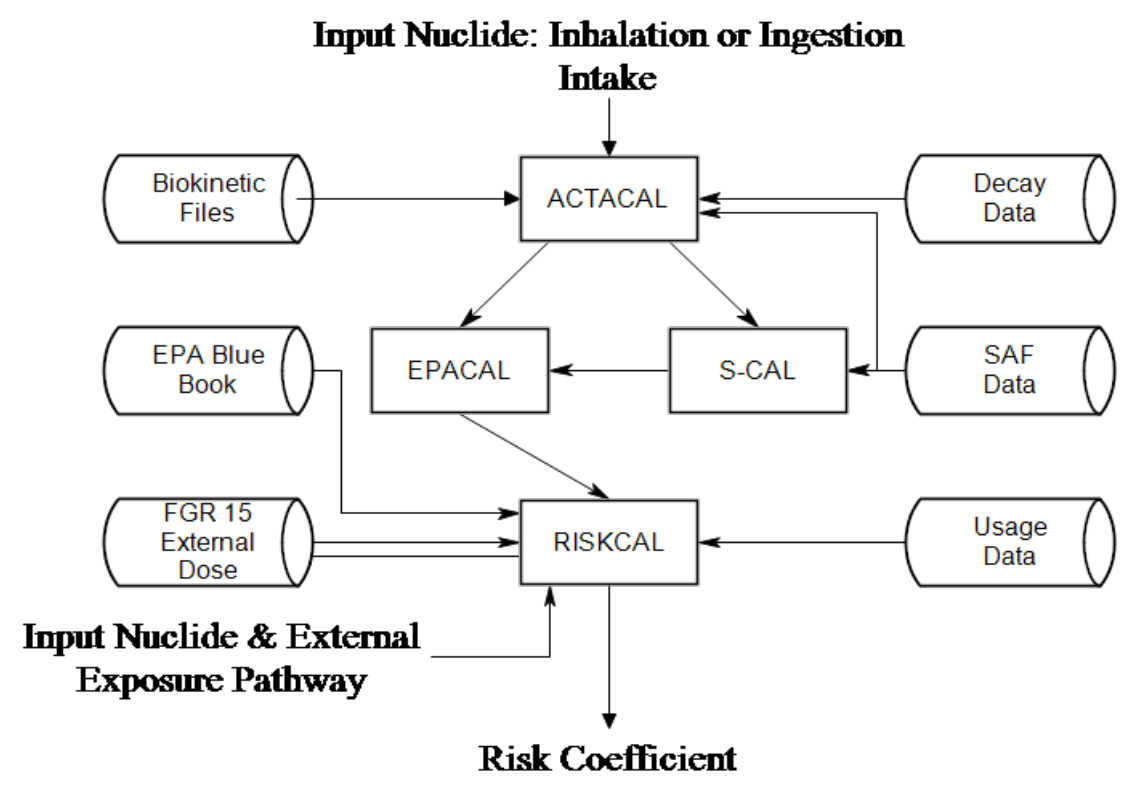

Figure 1: Schematic of the DCAL computational software.

All user input occurs within the ACTACAL module, which directs the other modules through a problemspecific file. The user input to ACTACAL identifies the radionuclide, intake route (inhalation, ingestion, or injection), and classification and age of the exposed individual(s) (occupational vs. public), and for ingested and inhaled activity identifies the chemical form and the aerosol size of material entering the respiratory tract. ACTACAL accesses several data files to assemble the compartmental models describing the behavior of the nuclide and any radioactive progeny produced in the body, solves the system of differential equations describing the kinetics of the radionuclides in the body, and generates an output file that directs the computations of other modules. The output file contains the activity of the radionuclide and its progeny present in each region of the body as a function of time post intake. The output file is read by S-CAL, which accesses nuclear decay data for the parent radionuclide and any radioactive progeny (ICRP, 2008) and the Specific Absorbed Fraction (SAF) data for each radionuclide (ICRP, 2020a). The resultant S-CAL output file contains coefficients representing the dose rate per activity present in each tissue identified in the biokinetic models. If ACTACAL is addressing nonadults the S-CAL addresses coefficients for six ages for which specific absorbed fraction data have been tabulated. EPACAL reads the output files of ACTACAL and S-CAL and outputs a file of the dose rate as a function of time post intake. The EPACAL output file for each of 12 files (representing 6 ages and both sexes) is passed to RISKCAL, which applies risk models defined in the EPA Radiogenic Cancer Risk Models and Projections for the U.S. Population, also known as the EPA Blue Book (EPA, 2011a) and usage data for environmental media from the EPA Exposure Factors Handbook (EPA, 2011b and updated portions of that report) to derive morbidity and mortality risk coefficients. ACTACAL's role in assembling and solving differential equations is the intensive computational effort within DCAL. The RISKCAL module also computes risk coefficients for external exposure to contaminated environmental media as shown in the graphic. The computation uses the external dose rate coefficients of Federal Guidance Report No. 15 (FGR-15), External Dose Coefficient for Radionuclides in Air, Water and Soil (Bellamy et al., 2019).

The ACTACAL module assembles the system of first-order ordinary differential equations (ODE) describing the fate of the radionuclide within the body including the ingrowth of radioactive progeny. For pre-adult ages the biokinetic transfer coefficients among the mathematical biokinetic compartments of the ODE are age (time) dependent. The resultant ODE system is solved using an elementary approximation technique developed by the ORNL team (Leggett et al., 1993). This solver has been used in DCAL for the 
past three decades (Eckerman et al., 2006). The number of differential equations to be solved depends on the number of mathematical compartments used to describe the kinetics of the internally deposited radionuclide and radioactive progeny, if any, produced in the body after intake of that radionuclide. Assembling the ODE for the system requires strict adherence to established DCAL guidelines. For example, the naming of the mathematical compartments must adhere to a convention, and the biokinetic files describing transfers of a radionuclide among those compartments must conform to a precise format.

\section{QCAL}

\subsection{HISTORY AND PURPOSE}

QCAL was developed by the ORNL dosimetry research team in 2015. Its initial purposes included substitution for DCAL while DCAL was undergoing revision to incorporate an updated ICRP biokinetic and dosimetric scheme, and QA of the revised DCAL. QCAL was used throughout 2015 and early 2016 as the primary code for dose and risk calculations for the Federal Guidance Project and work done for the Nuclear Regulatory Commission as an extension of that project. For QA purposes, hundreds of QCALgenerated dose coefficients and reference retention and excretion data for internally deposited radionuclides have been compared with values generated by dosimetry groups in other parts of the world. Also, risk coefficients generated by QCAL using the same models and other input files used in the development of FGR-13 (Eckerman et al., 1999) were compared extensively with risk coefficients published in FGR-13.

\subsection{SOFTWARE OVERVIEW}

QCAL consists of three separate programs: a Biokinetics code, a Dose Coefficients code, and a Risk Coefficients code. Figure 2 summarizes the three codes along with their inputs and outputs. The Biokinetics code produces activity as a function of time in source regions which serves as the input to the Dose Coefficients code. The Dose Coefficients code computes relative biological effectiveness (RBE) weighted dose rate coefficients as a function of time, which serve as input to the Risk Coefficients code. Finally, the Risk Coefficients code produces the risk coefficients desired for FGR-16. Therefore, the three codes must be run in sequence.

\section{SOURCES AND QUALITY ASSURANCE OF INPUT DATA}

Input information for DCAL and QCAL can be in the form of data related to basic nuclear decay, data describing biological processes or data describing physical phenomenon to be used in model execution. Table 1 and Figure 3 summarize the various data file groups and associated origin. This listing is not exhaustive of every source of data supporting the calculations, but instead identifies major input data. DCAL and QCAL generally source the same information, although it may be in different form. One difference between DCAL and QCAL is the stage at which radiation weighting occurs. DCAL utilizes a set of RBE-weighted SAFs, whereas QCAL applies the energy-dependent RBEs as it computes an Scoefficient internally. 
Input for Biokinetic Code

Source region masses

Biokinetic models

Respiratory tract

Alimentary tract

Systemic tissue

Physical half-life

Radioactive progeny

\begin{tabular}{l}
\hline Additional Input for Dose Coefficients \\
\hline Source region masses \\
List of target tissues \\
Radiation emissions data \\
Specific absorbed fractions \\
RBE \\
\hline
\end{tabular}

\section{Additional Input for Risk Coefficients}

Cancer risk models

Survival probability function

Cancer latencies

U.S. baseline cancer incidence and

mortality rates

Usage rates of contaminated medium

\section{Biokinetics}

$\sqrt{1}$

Activity as

function of time

$\sqrt{5}$

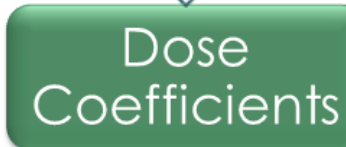

$\sqrt{2}$

RBE-weighted

dose rate as

function of time<smiles>[C]1=C[C]=C1</smiles>

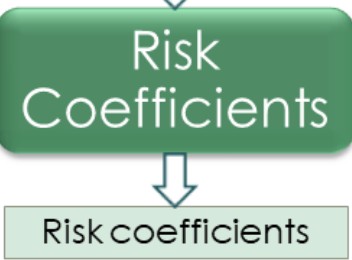

Other output for biokinetic code

Integrated activities

Bioassay data

Other output for dose coefficient code

Integrated activities

S-coefficients

Absorbed dose rate coefficients Committed absorbed dose coeffs

Committed equivalent dose coeffs

Committed effective dose coeffs

\section{Other output for risk code}

Sex-specific risk coefficients 
Figure 2: The three codes that comprise QCAL. On the left-hand side is input data for each code and the right-hand side lists output data.

Table 1. Reference data files

\begin{tabular}{lll}
\hline Data File Groups & Description & Source \\
\hline Nuclear Decay Data & $\begin{array}{l}\text { Four data files defining properties of the radiations emitted } \\
\text { by each of 1,252 radionuclides and copyright file. }\end{array}$ & ICRP (2008) \\
Biokinetic Data & $\begin{array}{l}\text { The biokinetic data defines the fate of inhaled and } \\
\text { ingestion radionuclides within the respiratory and } \\
\text { alimentary tract and that following uptake to blood. } \\
\text { 96 data files for 6 ages, 2 sexes, 4 radiations, 2 target } \\
\text { SAF Data }\end{array}$ & ICRP (2020a) \\
& $\begin{array}{l}\text { values (absorbed and RBE-weighted) plus 4 regional mass } \\
\text { files (source and target regions for 2 sexes). }\end{array}$ & ICRP (2016a, 2020a) \\
$\begin{array}{ll}\text { Lifetime Attributable } \\
\text { Risk }\end{array}$ & $\begin{array}{l}\text { Morbidity and mortality LAR file for 15 radiogenic } \\
\text { cancers, as a function of age for each gender. Also } \\
\text { included is the US life expectancy table for males and } \\
\text { females. } \\
\text { Age and sex specific usage of environmental media. }\end{array}$ & EPA (2011a) \\
Usage Data & $\begin{array}{l}\text { ICRP (1994b, 2002); EPA } \\
\text { (2011b) }\end{array}$ \\
$\begin{array}{l}\text { External Dose Rate } \\
\text { Coefficients }\end{array}$ & $\begin{array}{l}\text { Dose rate coefficients for external exposure to 1,252 } \\
\text { radionuclides in environmental media. }\end{array}$ & $\begin{array}{l}\text { FGR-15 (Bellamy et al., } \\
\text { 2019) and FGR-15 Viewer } \\
\text { (Eckerman et al., 2019) }\end{array}$ \\
\hline
\end{tabular}




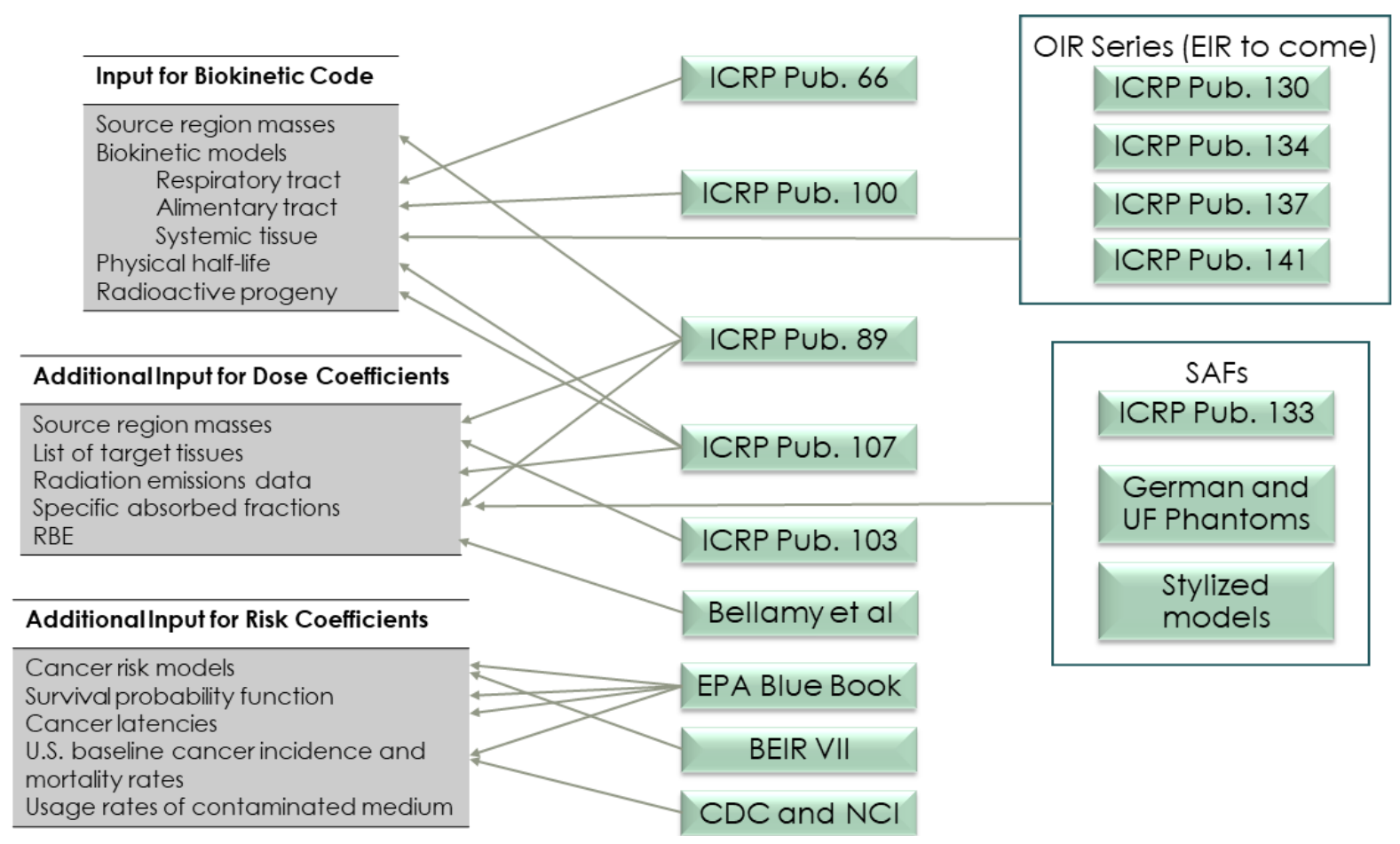

Figure 3. Published sources of input data. 


\subsection{USING PEER-REVIEWED AND PUBLISHED DATA AS SOURCES OF THE INPUT DATA}

Published data generally allow both the data and the methods used to produce the data to be checked and critiqued by independent peer-scientists. Sections in the text below describe the source and references for each of the Data File Groups used in DCAL and QCAL.

Much of the data and many of the input models used in DCAL and QCAL have been developed by, or in collaboration with, various ICRP working groups, and thus subject to considerable scrutiny and peerreview. The ICRP consists of the Main Commission, the Scientific Secretariat, four standing Committees, and Task Groups established as needed to undertake specific work. As described in the 2019 ICRP Annual Report (ICRP, 2020d):

Members come from over 30 countries and all disciplines relevant to radiological protection. They are invited to join ICRP as independent experts on a volunteer basis for four-year terms. Representatives of organizations in formal relations with ICRP are regularly invited to both advise the Main Commission and to participate in meetings of the Committees... This structure supports a rigorous system of peer review. The work of Task Groups is reviewed by the relevant Committee(s), and then reviewed and approved by the Main Commission. During development, most reports are circulated to a number of organizations and individual experts for critical review and posted for public consultation through the ICRP website (www.icrp.org).

\subsubsection{Nuclear Decay Data}

The nuclear decay data files, addressing 1,252 radionuclides, are the largest data files within DCAL or QCAL (>15 MB). This collection consists of an index file and three additional files. One of these files addresses the discrete alpha, electron (negatron and positron), and photon emissions of the radionuclides. The other two files detail the continuous beta and neutron spectra. The index file provides information needed for DCAL to assemble the decay chain, if any, headed by the radionuclide under consideration and information needed to directly access the nuclide's records in the other files. QCAL does not assemble the decay chain headed by the radionuclide under consideration but instead reads the chain members and the yield of each from a listing of previously assembled decay chains. The nuclear decay data files, assembled at ORNL, were distributed with ICRP Publication 107 (ICRP, 2008) through an international interaction of the Japan Atomic Energy Research Institute (JAERI), now the Japan Atomic Energy Agency (JAEA) and the US Environmental Protection Agency. This included an update of the EDISTR code (Dillman, 1980) used earlier to produce ICRP Publication 38 (ICRP, 1983). For QA and documentation of the updated EDISTR code see Endo, Yamaguchi, and Eckerman (2004), Endo (2005), and Endo and Eckerman (2007). These files are copyrighted by A. Endo and K.F. Eckerman as stated in the License.TXT file.

\subsubsection{Biokinetic Data}

The behavior of a radionuclide following its intake into the body is described in a large collection of data files. This information can vary with sex, age, nuclide, chemical form, particle size, and route of intake (in FGR-16, either ingestion or inhalation). The age and sex-specific Human Alimentary Tract Model (HATM) of ICRP Publication 100 (ICRP, 2006) and the age, sex, and chemical-form specific Human Respiratory Tract model of ICRP Publication 66 (ICRP, 1994a) as updated in ICRP Publication 130 (ICRP, 2015) are included (although sex-specific biokinetics is not addressed in FGR-16 because the preponderance of current biokinetic models do not address differences with sex). Element-specific models that project the behavior of radionuclides following uptake into blood are also included ("systemic models") (ICRP, 2020a). The updated version of DCAL includes files describing the projected behaviors of daughter products 
formed within the tissues of the body. The total collection of files describing the systemic behavior of parent and progeny radionuclides includes over 500 verified files. Some biokinetic files were assembled via a software module that reads published data tables. All files have been checked for adherence to DCAL format and naming convention using a software module.

\subsubsection{Phantoms and SAF Data}

The ICRP voxel suite of age and sex specific phantoms are used (ICRP, 2009, 2020c) when addressing radionuclide intakes. These phantoms characterize 77 anatomical regions (source regions) that may be identified in biokinetic models (respiratory and alimentary tract and systemic models) and 41 target tissues for which the absorbed dose may be of interest. The specific absorbed fraction (SAF) $(T \leftarrow S)$ quantity is the fraction of the energy emitted in source region $S$ that is absorbed per unit mass of target tissue $T$. These values were derived from Monte Carlo calculations applied to the reference phantoms and are tabulated for monoenergetic radiations (ICRP, 2020a). Data are provided for reference males and females as newborn, 1-y old, 5-y old, 10-y old, 15-y old and adults for alpha, electron, and photon radiations. Neutron specific SAF values are provided for the 28 radionuclides of ICRP Publication 107 (ICRP, 2008) that undergo spontaneous fission. The naming convention for the source and target regions of the body is consistent across 48 SAF files (and additional 48 RBE-weighted files of DCAL), together consisting of over 3 million individual data points; for adults, these data can be found in ICRP Publication 110 (ICRP, 2009). The data files for pre-adult ages are currently under review by Committee 2 of the ICRP (ICRP, 2020a). SAF files are used in QCAL and DCAL to derive radionuclide-specific levels of irradiation of tissues. In DCAL, all interpolations of SAF data are carried out within S-CAL using the Piecewise Cubic Interpolation Package (PCHIP) (Fritsch, 1982). In addition to the 96 SAF files, there are 4 files containing the age- and sexspecific masses of the source and target tissues.

The QA for SAF data is a multi-step process, conducted mostly in house within CRPK. Briefly, this includes (1) comparing limiting SAF (i.e., SAF at $0 \mathrm{MeV}$ ) within SAF files to theoretical values and for different ages, sexes, and radiation types; (2) reviewing graphs of SAF vs. energy to check for consistency, scientific plausibility, and typos (e.g., Figure 4); (3) summarizing details for collaborative review; and (4) implementing corrections as needed.
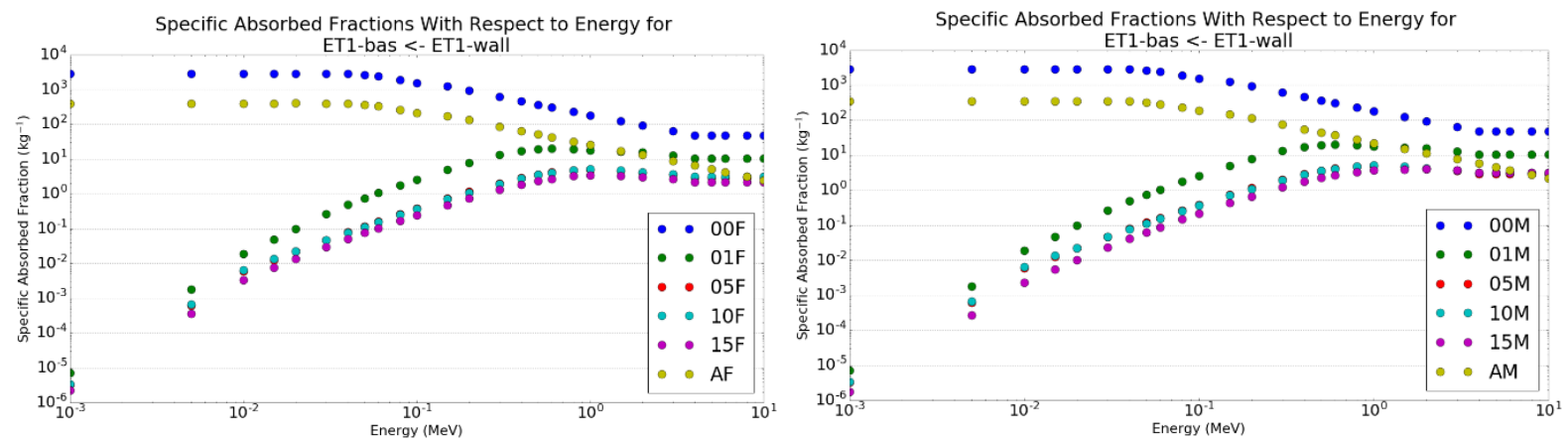

Figure 4: Example visualization of select SAFs vs. energy for QA review. For certain ages, electron SAFs for ET1-bas $\leftarrow$ ET1-wall were switched in both sexes; QA enabled changes to be implemented prior to final calculation of dose and risk coefficients. 


\subsubsection{Lifetime attributable risk (LAR)}

The LAR coefficients detailed in the EPA Blue Book (EPA, 2011a) address the lifetime male and female cancer morbidity and mortality due to a unit dose experienced as a function of age. For the most part the LAR coefficients are based on risk models recommended in the National Academy of Sciences' BEIR VII report (NAS, 2006). The fifteen cancers considered are stomach, colon, liver, lung, breast, prostate, uterus, ovary, bladder, thyroid, skin, leukemia, kidney, bone, and residual. In addition, a file representing a recent US decennial life table is included. All information is contained in two files. These files are provided by EPA, and ORNL has performed an independent verification.

\subsubsection{Usage Data}

A risk coefficient for a radionuclide and exposure pathway assumes a constant concentration of the radionuclide in the pertinent environmental medium. The usage level of the medium may depend on age and sex. Age- and sex-specific breathing rates are assumed for the inhalation intakes based on rates tabulated in ICRP Publications 66 and 89 (ICRP, 1994a, 2002). Ingestion intakes for food are based on ageand sex-specific caloric needs and published water intake levels for recent US populations (EPA, 2011b).

\subsubsection{External Dose Coefficients (DCAL)}

FGR-15 age and sex specific external dose coefficients files are used by the RISKCAL module to derive the morbidity and mortality coefficients for external exposure to contaminated environmental media. These files provide the dose rate coefficients for the tissues of the body. The files are as included with the FGR15 Viewer (Eckerman et al., 2019) and provide the equivalent dose rate coefficient for 29 tissues of the body for 1252 radionuclides; as only electrons and photons are involved, the coefficients represent the absorbed dose rate. The environmental media include air, water, ground surface, and sources distributed uniformly in the ground to depths of $1 \mathrm{~cm}, 5 \mathrm{~cm}, 15 \mathrm{~cm}$ and infinite. These data are not based on a pending ICRP publication but have been compared with the ICRP data and are generally consistent with those data.

\subsection{NOT ALTERING THE DATA FILES FROM THEIR ORIGINAL FORM}

Where feasible, data sets are used in raw format without alteration to ensure that CRPK is using the same data files as other users including ICRP task groups and EPA staff. ICRP Publication 107 (nuclear decay data), Publication 133 (specific absorbed fractions), and systemic biokinetic files (.def files) are three examples of downloadable data used by multiple users in the form of text files (ICRP, 2008, 2016a). Use of raw data simplifies version control as well as error correction when an outside user discovers a problem with the data.

\subsection{USING VERSION CONTROL FOR DEVELOPMENT OF INPUT DATA}

Portions of the original input data sets have been prepared by CRPK (for example, specific absorbed fractions, tissue masses, and transfer coefficients defining the systemic biokinetic models). Version control software such as Git and cloud repositories such as Github or Bitbucket allow for the tracking of changes to such files during their preparation. Figure 5 shows a screenshot of the cloud repository used along with Git to track changes (commits) made to the input data of QCAL. It provides a historical record and, if needed, old data can be restored. 


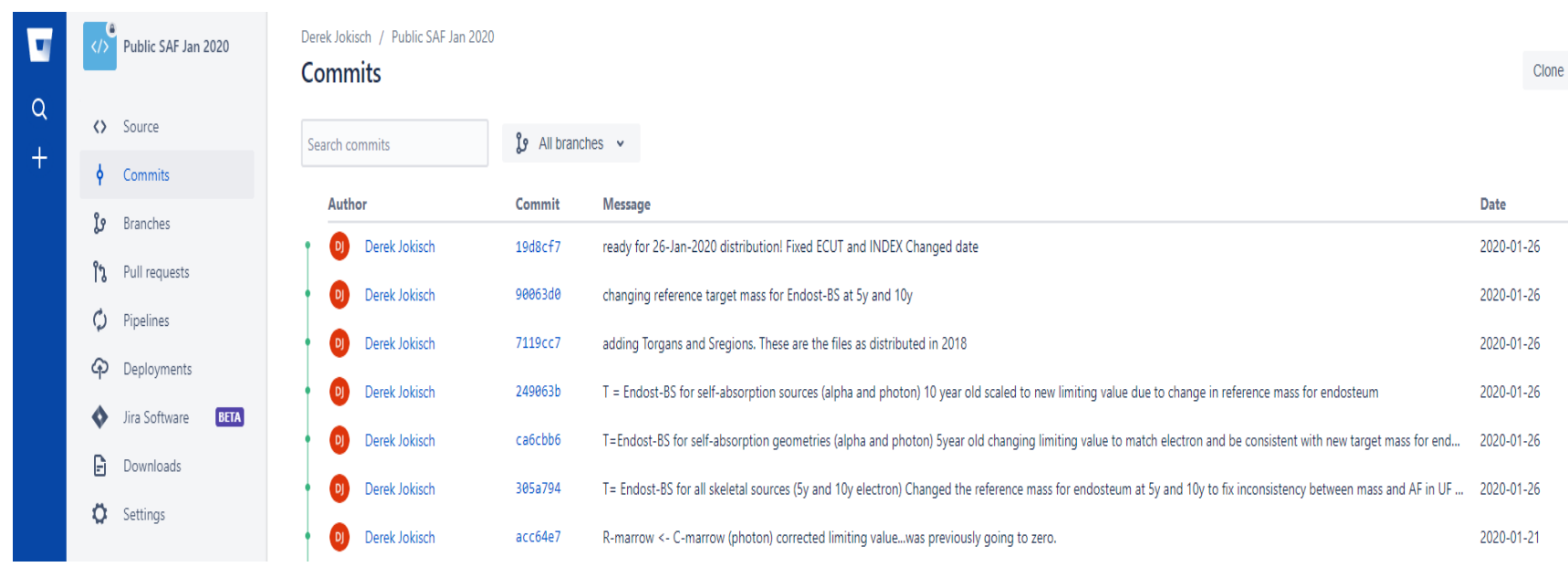

Figure 5: Screenshot of a cloud repository coupled with Git for SAF development.

\subsection{ANALYSIS OF OUTPUT DATA (RESULTS)}

Based on past calculations and an understanding of biokinetics and radiation dosimetry, several types of output can be analyzed to make sure they match logical expectations. For example, it is well known that upon intake, radioiodine is delivered primarily to the thyroid gland. It is therefore expected for the preponderance of nuclear transformations to occur in the thyroid gland and the dose to the thyroid to be dominant. Figure 6a displays results from QCAL that match expectations. Age-dependent changes in these quantities can also be analyzed. As expected, no significant age-dependency is found in the calculated decays of ${ }^{131} \mathrm{I}$ in the thyroid gland. Figure $6 \mathrm{~b}$ shows the expected significant age-dependency resulting from the increasing thyroid mass with age.

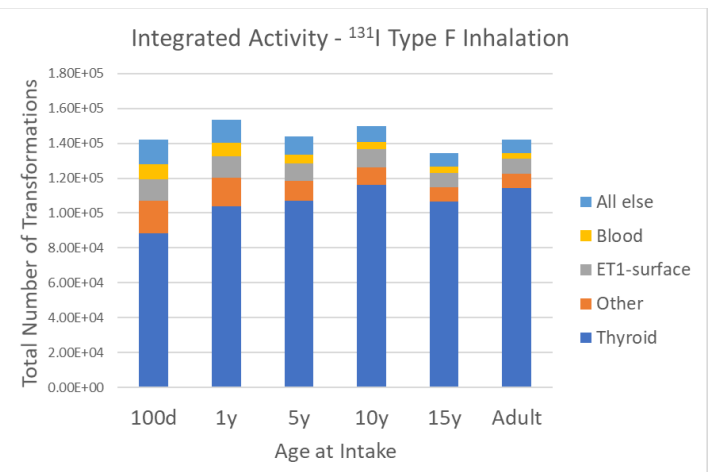

Figure 6a: Number of nuclear transformations (integrated activity) broken up by source region for each age of intake.

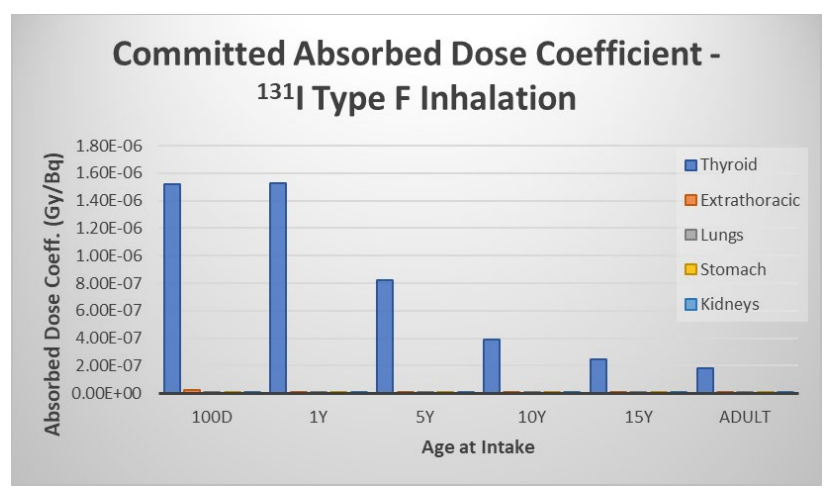

Figure 6b: Committed absorbed dose coefficient for inhalation of type F I-131 for each reference age of intake. 


\section{SOURCES AND QUALITY ASSURANCE OF MODELS}

As with input data, the biokinetic and dosimetric models selected for use within QCAL and DCAL are models recently published by the ICRP or to be published in upcoming ICRP reports. Some of these models were originally published in the open literature and later adopted by the ICRP for use in ICRP reports. Other models were developed by members of ICRP task groups for use in ICRP documents. In either case, the models have undergone validation by ICRP task groups and, for models taken from the literature, some level of validation by the original developers of the models.

The validation process for a model involves critical evaluation of the method of model construction including the logical foundation of the model structure; the strength of the database and its relevance to healthy human populations; and the rationale for selection of parameter values, which in many cases includes the basis for emphasizing specific portions of the database. The model validation process includes comparison of model predictions with independent observations made since the models were developed when such data are available.

In DCAL, all user input occurs within the first module, called ACTACAL. That module creates an output file, referred to as a LOG file, that records the user input, checks on that input, and identifies all data files accessed in processing the user's input. The name of the data file, its date of creation, and its size (kilobytes) are recorded in the LOG file. All successive computational modules append the identity of data files they access to the LOG file. In addition, the date that the computational module was compiled, and its file size are recorded in the LOG file. DCAL provides a graphic display of the activity of the nuclide and its progeny within the source region of the body and the dose rate in the target tissues as a function of time post intake. Calculations performed using DCAL inherit a pedigree from the computational modules and the various permanent data files (libraries) used in the calculations.

\subsection{INHALATION}

DCAL and QCAL use the Human Respiratory Tract Model (HRTM) initially published in ICRP Publication 66 (ICRP, 1994) and updated in ICRP Publications 130 (ICRP, 2015). Inhaled particulate matter deposits in both the extrathoracic airways and the thoracic region of the respiratory tract. The fraction of the inhaled activity deposited in these regions depends on the aerosol size and the physical activity of the subject. Members of the public are assumed to be involved in four general types of activity (sleep, sitting, light exercise, and heavy exercise) involving different breathing rates and time periods. The typical activityweighted deposition in the various regions of the respiratory tract as estimated by an ICRP task group (the female specific depositions are based on Klumpp and Bertelli (2017)) is shown in Table 2. Also shown in Table 2 is the activity weighted daily air intake. 
Table 2. Regional deposition of aerosol (1 $\mu$ m AMAD) for reference individuals.

\begin{tabular}{|c|c|c|c|c|c|c|}
\hline \multirow[b]{3}{*}{ Compartments } & \multicolumn{6}{|c|}{ Deposition (\%) } \\
\hline & \multirow[b]{2}{*}{ 3-month old } & \multirow[b]{2}{*}{ 1-y old } & \multirow[b]{2}{*}{ 5-y old } & \multirow[b]{2}{*}{ 10-y old } & \multirow{2}{*}{$\begin{array}{l}\text { 15-y old } \\
\text { Male/Female } \\
\end{array}$} & \multirow{2}{*}{$\begin{array}{l}\text { Adult } \\
\text { Male/Female }\end{array}$} \\
\hline & & & & & & \\
\hline \multicolumn{7}{|c|}{ Extrathoracic (ET) Region } \\
\hline $\mathrm{ET}_{1}$ & 31.31 & 31.44 & 25.81 & 26.40 & $20.83 / 21.20$ & $22.01 / 22.42$ \\
\hline $\mathrm{ET}_{2}$ & 16.86 & 16.93 & 13.90 & 14.21 & $11.21 / 11.93$ & $11.85 / 12.21$ \\
\hline \multicolumn{7}{|l|}{ Thoracic Region } \\
\hline Bronchial (BB) & 1.04 & 1.04 & 1.03 & 1.17 & $1.69 / 1.67$ & $1.29 / 1.29$ \\
\hline Bronchiolar $(\mathrm{Bb})$ & 2.05 & 1.71 & 1.85 & 1.70 & $2.00 / 1.99$ & $1.95 / 2.11$ \\
\hline $\begin{array}{l}\text { Alveolar- } \\
\text { Interstitial (AI) }\end{array}$ & 8.56 & 9.64 & 9.85 & 9.51 & $10.65 / 10.46$ & $11.48 / 10.84$ \\
\hline Total & 59.82 & 60.76 & 52.44 & 52.99 & $46.38 / 47.26$ & $48.58 / 48.86$ \\
\hline Daily Intake $\left(\mathrm{m}^{3}\right)$ & 2.86 & 5.16 & 8.72 & 15.3 & $20.1 / 15.7$ & $22.2 / 17.7$ \\
\hline
\end{tabular}

The deposited activity is cleared from the respiratory tract by mechanical transfer out of the airways and by uptake to blood. The transfer to blood is treated as a two-stage process involving dissociation of the radionuclide from the inhaled particles and subsequent absorption of the radionuclide. The rates for these processes are time dependent, with a fraction considered to dissolve relatively rapidly and the remaining fraction to dissolve more slowly. The updated respiratory model of ICRP Publication 130 includes consideration of a bound fraction for certain elements, i.e., a fraction of the inhaled amount that is retained for an element-specific period within the walls of the airways (ICRP, 2015). The chemical and physical nature of the aerosol is assumed to determine the dissolution and absorption dynamics of inhaled activity deposited in the respiratory tract. Three standard absorption rates are defined: fast (Type F), moderate (Type $\mathrm{M}$ ) and slow (Type S). A fourth absorption type (Type V; very fast) is applicable to gases and vapor forms. For these chemical forms, $100 \%$ of the inhaled activity generally is assumed to be instantaneously absorbed and transferred to blood.

\subsection{GUT}

The ICRP's Human Alimentary Tract Model (HATM) (ICRP, 2006) depicts the movements of material entering the alimentary tract following intake into the oral cavity (ingestion) or transferred to the esophagus after clearance from the respiratory tract (inhalation). The model depicts the sequential transfers through the alimentary tract and potential systemic uptake (transfer to blood). Reference age-specific transfer rates through different segments of the alimentary tract are shown in Table 3. 
Table 3. Age-specific HATM transfer coefficients for total diet*

\begin{tabular}{|c|c|c|c|c|c|}
\hline \multirow[b]{2}{*}{ From } & \multirow[b]{2}{*}{ To } & \multicolumn{4}{|c|}{ Transfer coefficient $\left(d^{-1}\right)$} \\
\hline & & 3-month old & 1-y old & $5-15$ y old & Adults** \\
\hline Oral-cavity & Esophagus-fast & 38880 & 6480 & 6480 & 6480 \\
\hline Oral-cavity & Esophagus-slow & 4320 & 720 & 720 & 720 \\
\hline Esophagus-fast & Stomach & 21600 & 12343 & 12343 & 12343 \\
\hline Esophagus-slow & Stomach & 2880 & 2160 & 2160 & 2160 \\
\hline Stomach & Small Intestine & 19.2 & 20.57 & 20.57 & $20.57 / 15.16$ \\
\hline Small Intestine & Right Colon & 6 & 6 & 6 & 6 \\
\hline Right Colon & Left Colon & 3 & 2.4 & 2.182 & $2 / 1.5$ \\
\hline Left Colon & Rectosigmoid & 3 & 2.4 & 2.182 & $2 / 1.5$ \\
\hline Rectosigmoid & Feces & 2 & 2 & 2 & $2 / 1.5$ \\
\hline \multicolumn{6}{|c|}{$\begin{array}{l}* \text { The transfer coefficient to blood from the small intestine is } f_{A} \lambda_{\mathrm{SI}, \mathrm{RC}} /\left(1-f_{A}\right) \text { where } f_{\mathrm{A}} \text { is the fraction of the } \\
\text { stable element absorbed from the alimentary tract and } \lambda_{\mathrm{SI}, \mathrm{RC}} \text { is the age-invariant transfer coefficient from the } \\
\text { small intestine to the right colon. } \\
* * \text { Sex specific coefficients (male/female) are specified for adults in the removal from the stomach, right colon, } \\
\text { left colon and rectosigmoid. }\end{array}$} \\
\hline
\end{tabular}

\subsection{SYSTEMIC BIOKINETIC MODELS}

Element-specific systemic biokinetic models depict the fate of radionuclides absorbed from the alimentary or respiratory tract to blood. The transfer to blood results in the nuclide being widely distributed among body tissues and its potential entrance into metabolic processes. The tissue-specific metabolic processes can result in the nuclide being incorporated into body tissue, e.g., in mineral bone, entering metabolic processes, or simply stored in tissues. The radionuclide can be eliminated by the filtering action of the kidneys, which result in its transfer to the urinary bladder content, or by secretion from the liver or other organs to the contents of the alimentary tract. For activity secreted into the contents of the alimentary tract, the potential for reabsorption to blood is also considered in the systemic models. The nature of these processes is dependent on chemical and physiological processes, which vary across the elements.

The fate of radioactive progeny formed within the systemic tissues must also be addressed. The systemic models for progeny generally depict "independent kinetics" of chain members produced in systemic pools. This means that progeny produced in systemic compartments are assumed to follow their characteristic systemic behavior rather than that of the parent. In the past, radioactive progeny were often assigned the same model as the parent (so-called shared kinetics), in contrast to the assumption of independent kinetics of progeny as now applied in the ICRP's biokinetic modeling approach.

\section{QUALITY ASSURANCE OF SOFTWARE}

It is also important that steps are taken to gain confidence that the codes are computationally correct. It is possible for errors to be introduced both in design and implementation. Design errors result from the programmer designing an algorithm that does not accurately describe the phenomenon under consideration. Implementation errors result when a programmer fails to code an algorithm properly. The methods described below allow ORNL to have confidence that both design and implementation errors have been eliminated from DCAL and QCAL.

\subsection{INTERNAL COMPARISONS}

The first-order biokinetic model solver used in both DCAL and QCAL is an approximation technique developed by ORNL's dosimetry research team (Leggett et al., 1993). The ORNL solver has been verified 
by extensive comparisons with other widely used solvers for biokinetic models and systems of differential equations, some of which provide virtually exact solutions. Checks of the ORNL solver against independent codes with much different solvers have been published (Leggett et al., 1993). Over the past three decades, the solver has been checked extensively against independent solvers used by ICRP contributors across the world.

A limitation of early comparisons of DCAL with other solvers has been that the other solvers are generally more limited regarding the size of the model that can be addressed. One of the conventional solvers against which DCAL has been checked is the ORNL code DIFSOL (Killough and Eckerman, 1984), which is built around routines from EISPACK, a widely used collection of state-of-the-art software for eigensystem analysis (Smith et al., 1976). The original DIFSOL code was constrained to a relatively small number of coupled differential equations and thus to biokinetic models with relatively few transfer coefficients. In recent work for the Nuclear Regulatory Commission (NRC), ORNL has modified DIFSOL to handle some of the more complex recycling biokinetic models used in ICRP reports. Additional tests of the DCAL solver have been made by comparison of predictions of these more complex models based on DCAL and DIFSOL. Close agreement between DCAL and DIFSOL solutions were found in all cases. As DCAL is widely distributed, it has been used by many investigators to benchmark their calculations for a nuclide of interest using commercial software applications. DCAL and DIFSOL comparisons were documented in the DCAL manual (Eckerman et al., 2006) and in the paper by Leggett et al. (1993) and will be documented in the updated DCAL manual to be published following the release of FGR-16 and after ORNL publication clearance.

\subsubsection{Comparisons between DCAL and QCAL}

QCAL's original development was driven by a need to generate dose or risk coefficients or reconstruct doses from bioassay data while DCAL was being updated. QCAL will now also serve as a benchmark for the updated DCAL, whose distribution is to accompany the publication of FGR-16. Table 4 summarizes the components of both DCAL and QCAL and the output data which they have in common.

Table 4. Comparisons between DCAL and QCAL

\begin{tabular}{lll}
\hline DCAL subroutine & Output to be compared & QCAL code \\
\hline ACTACAL & Integrated activities & Biokinetics \\
\hline S-CAL & $\begin{array}{l}\text { S-coefficients } \\
\text { Committed equivalent dose coefficients } \\
\text { Committed effective dose coefficients } \\
\text { RPACAL }\end{array}$ & \multirow{2}{*}{ Dose Coefficients } \\
\hline \multirow{2}{*}{ RISKCAL } & $\begin{array}{l}\text { Sex-specific risk coefficients } \\
\text { Sex-averaged risk coefficients }\end{array}$ & \multirow{2}{*}{ Risk Coefficients } \\
\hline
\end{tabular}

The DCAL and QCAL output will be compiled and shared with all code developers. Any differences are discussed, and the bases of those differences are tracked down. If this process results in a component of a program being modified, the process is repeated.

\subsubsection{Comparisons with FGR-13}

Note that comparisons with international codes can provide confidence in the biokinetics and dose coefficients programs of DCAL and QCAL (section 6.2) but will not speak to risk coefficients. This is because the EPA FGR risk calculations are currently unique to the United States. To address the need for gaining confidence in computed risk coefficients, comparisons can be made (1) between DCAL and QCAL as above and (2) between the output of these codes and prior risk coefficients computed in FGR-13. It is important to note that we do not expect identical results to FGR-13, but differences that arise should be understandable. Figure 7 gives an example of such comparisons. 


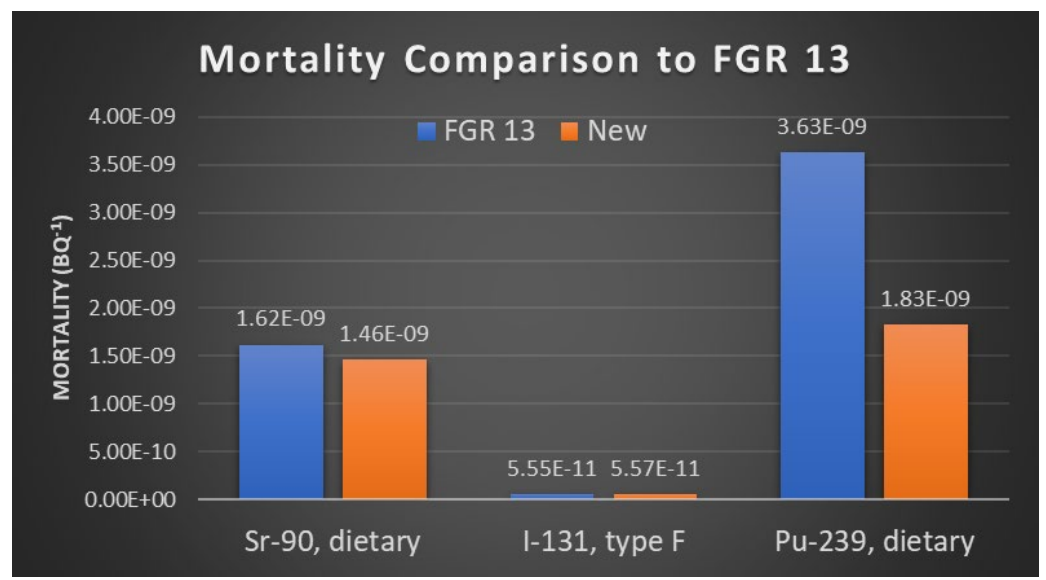

Figure 7: Mortality comparison between QCAL and FGR 13 for three example cases.

\subsection{EXTERNAL COMPARISONS}

CRPK is actively involved in the latest development of ICRP dose coefficients for workers and members of the public. The biokinetic model describing transfer through the alimentary tract and nearly all the systemic biokinetic models were developed by the CRPK. Respiratory models were developed primarily at Public Health England (PHE), with input from CRPK. DCAL and QCAL use the same biokinetic models, nuclear decay data, and SAFs as those used by members of task groups of ICRP Committee 2. DCAL and QCAL have been used to derive or check the values given in several ICRP documents.

Moreover, output is produced that is supplemental to risk coefficients, and since the various forms of output are tied to the same calculations, this provides additional opportunities for comparisons to other dose calculation codes and programs. Colleagues at PHE, the Ukrainian Radiation Protection Institute, and the German Office for Radiation Protection each have internal dosimetry codes being utilized for different aspects of this work. Each of these codes were independently written. In other words, code was not shared, although each code utilizes the same input data. Methods, however, were discussed and shared. Dose coefficients and bioassay data have been distributed to the cooperating institutions for comparison of results. If close agreement among all participating groups is not achieved for a given calculation, the organizations drill down to find the source of the discrepancy. The models are finalized when results from all institutions compare within a small tolerance level. Representative of these comparisons, Figure 8 shows the various QCAL output and its comparisons to output from other sources. For additional insight into the past QA/QC effort on DCAL, see the document entitled "FGR13QA.pdf" which is included in the FGR-13 CD Supplement distributed by EPA (Eckerman and Leggett, 2002). 


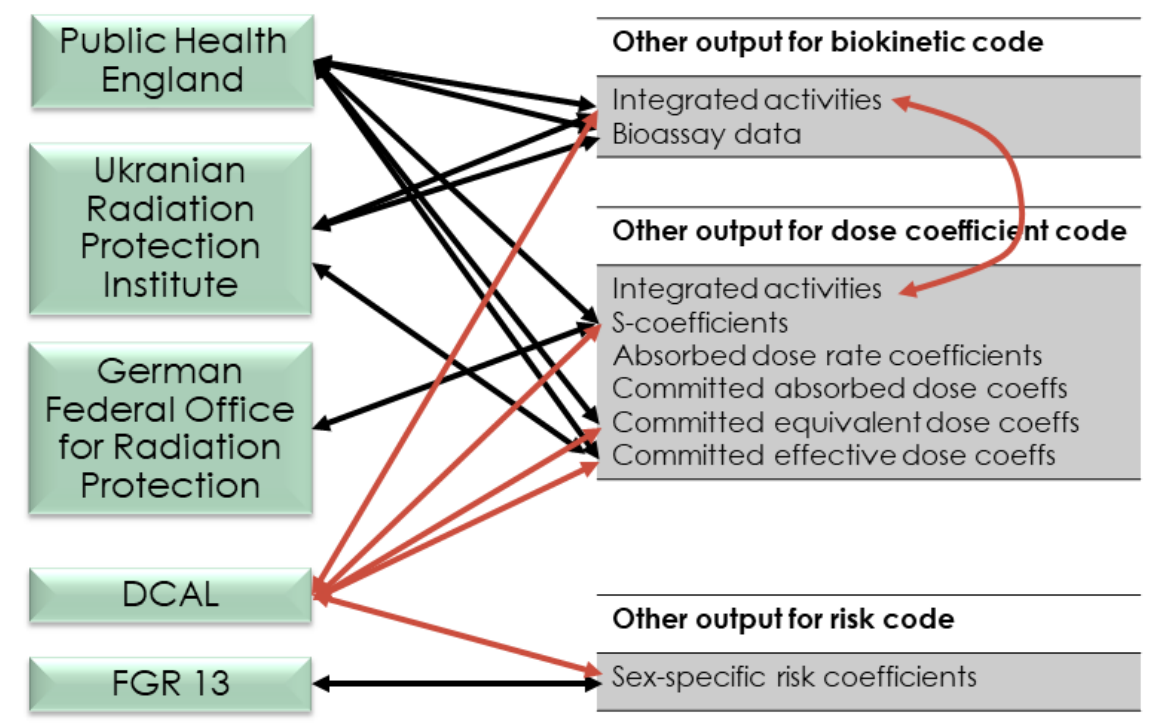

Figure 8: Summary of the comparisons of QCAL output data with other sources of the same output, including DCAL.

\subsection{VERSION CONTROL AND ARCHIVING}

The DCAL software and data files are archived on the version control system known as Git for storage so that any subsequent changes to code or supporting data can be sufficiently tested. Any future change to either the DCAL algorithms or the supporting nuclear decay and biokinetic data will be recorded and results of this process archived and noted in a log file maintained by Git. Within the Git framework, every version of a code resides in the Git repository, and the history of changes is kept so that developers can refer to any change made in the code development process. All data files utilized by DCAL will be placed in the Git repository as well, so that modifications to the data can be easily tracked. The content of the files in the Git repository is secured with a cryptographically secure hashing algorithm, which protects the code and change history against accidental and malicious change and whose change history is fully traceable. In addition, during their use within DCAL the integrity of the data files can be tested via a Cyclic Redundancy Code (CRC) (Koopman et al., 2015). The CRC computed for a file is compared to its reference value established at the time the file was established. DCAL invokes a software module that computes for all reference files their CRC values and compares with values assigned at the time DCAL was released as requested by the user. If the file integrities are not confirmed, DCAL advises the user to reinstall the DCAL software and then shuts down.

Version control software (Git) and a cloud repository have been used throughout development and revision of QCAL. This allows for easy and frequent tracking of changes made to the code. Importantly, it also allows for descriptions of justifications for each change. If a change proves to be undesirable, old code can easily be accessed and restored. Figure 9 is a screenshot of one example of a change (commit) made to the code. Additionally, generated output files from QCAL are stamped with a version date which corresponds to the compilation date of the program used to create the output. When combined with the code's version control and cloud repository described earlier, output files are easily matched with the version of the code (and its methods) which produced it. This minimizes the risk of confusing output generated by older versions of the code as being up-to-date. 


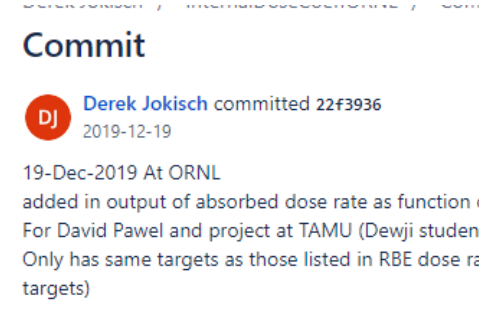

Figure 9: Git cloud repository screenshot for QCAL. It shows the details of one particular change (commit).

\author{
(commit).
}

\subsection{DCAL BETA TEST FEEDBACK AND IMPLEMENTATION}

Past versions of DCAL were distributed to a set of beta testers for comments prior to release. DCAL has been freely and widely distributed within the health physics, nuclear medicine, and university communities. Comments and suggestions received for beta testing were reflected in the released DCAL versions. The updated DCAL will be forwarded to a set of beta testers prior to its final release. DCAL continues to be a Windows-based application. While the updated DCAL user-interface has changed little, it potentially will be installed on laptops and desktops running different versions of Windows with monitors of varying resolution. These aspects as well as any numerical verification that the beta testers might provide are of importance to the final release.

Beta testers will be provided a series of questions related to both the usability and numerical output of DCAL. Responses and other comments will be collected by email, consolidated, and reviewed by the CRPK and EPA Federal Guidance Team. Changes relevant to the content and results of FGR-16 will be implemented and documented within the corresponding code. Other feedback (e.g., on aesthetics) will be implemented at the discretion of the team.

\section{ASSESSMENT AND RESPONSE ACTIONS}

The work undertaken by CRPK undergoes two separate considerations during production and publication. Internal program assessment seeks to determine that models and data are correct for the intended purpose. Material submitted by ORNL staff for publication in any form must undergo an ORNL review process called the RESolution Publication System (ORNL, 2019). The RESolution process is intended to assure high scientific and literary quality and transparency of ORNL publications, maintain complete records of all ORNL publications, and allow electronic access to ORNL's open literature publications (OSTI). 
The primary method for assessment of results involves comparison with previous documents and comparisons using different codes (internal and external). Assessment is a continuous process between researchers developing the code and others performing verifications against similar calculations using other codes. The internal program assessment is an investigator-driven process that takes place from the beginning of the development of biokinetic models all the way to overall software development for calculation of dose coefficients and risk. At each stage, all aspects of CRPK work is evaluated for correctness by crosstalk within the CRPK and by consultation with national and international collaborators.

Corrective actions will be pursued if it is learned that incorrect or faulty models were being used, or that unproven software was being employed. The general process will involve documentation of the observed discrepancy or error, notification of affected team members, identification of the root cause and associated solutions to the underlying problem, implementation of the response action, and monitoring the outcome. The response action will be commensurate with the problem discovered. For example, if an individual observes in a timely manner a minor mistake during review of their own work that has not impacted downstream work, the mistake, cause, and solution will be documented in their notebook or code and the correction made. On the other hand, if a significant error is discovered during review of the full FGR-16 report, a team approach to identifying the root cause and appropriate response will be employed. 


\section{REFERENCES}

Bellamy, M.B., S.A. Dewji, R.W. Leggett, M. Hiller, K. Veinot, R.P. Manger, K.F. Eckerman, J.C. Ryman, C.E. Easterly, N.E. Hertel, and D.J. Stewart, 2019. External Exposure to Radionuclides in Air, Water, and Soil. Federal Guidance Report No. 15, EPA-402/R19/002.

Dillman, L.T., 1980. EDISTR: A Computer Program to Obtain a Nuclear Decay Data Base for Radiation Dosimetry, ORNL/TM-6689.

Eckerman, K.F., R.W. Leggett, C.B. Nelson, J.S. Puskin, A.C.B. Richardson. 1999. Cancer Risk Coefficients for Environmental Exposure to Radionuclides. Federal Guidance Report No. 13, EPA 402R-99-001.

Eckerman, K.F. and R.W. Leggett, 2002. FGR-13 Quality Assurance Efforts. Federal Guidance Report No. 13: CD Supplement.

Eckerman, K.F., R.W. Leggett, M. Cristy, C.B. Nelson, J.C. Ryman, A.L. Sjoreen, and R.C. Ward, 2006. User's Guide to the DCAL System, ORNL/TM-2001/190.

Endo, A., Y. Yamaguchi, and K.F. Eckerman, 2004. Nuclear Decay Data for Dosimetry Calculation, JAERI 1347.

Endo, A., 2005. Nuclear Decay Data for Dosimetry Calculations. Supplement to JAERI 1347.

Endo, A. and K.F. Eckerman, 2007. Nuclear Decay Data for Dosimetry Calculations, JAEA-Data/Code 2007-021.

EPA, 2011a. EPA Radiogenic Cancer Risk Models and Projections for the U.S. Population. U.S. Environmental Protection Agency, Washington, DC.

EPA, 2011b. Exposure Factors Handbook 2011 Edition (Final Report). U.S. Environmental Protection Agency, Washington, DC, EPA/600/R-09/052F.

Fritsch, F. N. Piecewise Cubic Hermite Interpolation Package. Final specifications. United States: N. p., 1982. Web. doi:10.2172/6838406.

ICRP, 1983. Radionuclide Transformations, Energy and Intensity of Emissions. ICRP Publication 38, Ann. ICRP 11-13.

ICRP, 1994a. Human Respiratory Tract Model for Radiological Protection. ICRP Publication 66. Ann. ICRP 24(1-3).

ICRP, 1994b. Dose Coefficients from Intakes of Radionuclides By Workers. ICRP Publication 68. Ann. ICRP 24(4).

ICRP, 2002. Dose to the Embryo and Fetus from Intakes of Radionuclides By the Mother. ICRP Publication 88. Ann. ICRP 31(1-3).

ICRP, 2006. Human Alimentary Tract Model for Radiological Protection. ICRP Publication 100. Ann. ICRP 36(1/2). 
ICRP, 2008. Nuclear Decay Data for Dosimetric Calculations. ICRP Publication 107. Ann. ICRP 38(3).

ICRP, 2009. Adult Reference Computational Phantoms. ICRP Publication 110. Ann. ICRP 39(2).

ICRP, 2015. Occupational Intakes of Radionuclides: Part 1. ICRP Publication 130. Ann. ICRP 44(2).

ICRP 2016a. The ICRP Computational Framework for Internal Dose Assessment for Reference Adults: Specific Absorbed Fractions. ICRP Publication 133. Ann. ICRP 45(2).

ICRP, 2020a. The ICRP Computational Framework for Internal Dose Assessment for Members of the Public: Specific Absorbed Fractions. Ann. of the ICRP (in preparation).

ICRP, 2020b. Environmental Intakes of Radionuclides: Part 1. Ann. of the ICRP (in preparation).

ICRP, 2020c. Paediatric Reference Computational Phantoms. ICRP Publication 143. Ann. of the ICRP (in press).

ICRP, 2020d. ICRP 2019 Annual Report. ICRP Ref No. 4843-6284-6665. Available at: http://icrp.org/admin/2019\%20ICRP\%20Annual\%20Report.pdf

Killough, G.G. and K.F. Eckerman, 1984. A Conversational Eigen analysis Program for Solving Differential Equations, In: Computer Applications in Health Physics, 4.49-4.58. Proceedings of the 17th Midyear Topical Symposium of the Health Physics Society. Eds. R. L. Kathern, D. P. Higby, and M. A. McKinney.

Klumpp, J. and L. Bertelli, 2017. KDEP: A Resource for Calculating Particle Deposition in the Respiratory Tract, Health Physics 113: 110-121

Koopman P., K. Driscoll, and B. Hall, 2015. Selection of Cyclic Redundancy Code and Checksum Algorithms to Ensure Critical Data Integrity, DOT/FAA/TC-14/19.

Leggett, R.W., K. F. Eckerman, and L.R. Williams, 1993. An Elementary Method for Implementing Complex Biokinetic Models, Health Phys 64: 260-278.

NAS, 2006. Health Risks from Exposure to Low Levels of Ionizing Radiation. BEIR VII Phase 2. National Academy Press: Washington, D.C.

ORNL, 2019. RESolution [online]. Available at: https://web.ornl.gov/RES/. Accessed May 24, 2020.

Smith, B.T., J.M. Boyle, J.J. Dongarra, B.S. Garbow, Y. Ikebe, V.C. Klema, and C.B. Moler, 1976. Matrix Eigensystem Routines-EISPACK Guide. Springer-Verlag: New York. 